\title{
The Effect of Applying Business Intelligence on Improvement of Information Technology Management (Case Study: Software Companies in Tehran Province)
}

\author{
El efecto de la aplicación de Business Intelligence en la mejora de la gestión \\ de la tecnología de la información (Estudio de caso: empresas de software en \\ la provincia de Teherán)
}

\section{Mohamad Ali Noruozzadeh' ${ }^{1}$ (D)}

I Faculty of Management \& Economics, Science and Research Branch, Tehran, Iran.

\begin{abstract}
The purpose of this study was investigating the effect of applying business intelligence in improving information technology management of organization based on data of software companies in Tehran province using data mining techniques in Clementine environment entitled BI-IT.DM. The data is based on a sample of 12,000 data and reports from software companies in Tehran province during the years 2013 to 2018, available in the Organization of Computer Guild of Iran. The initial and proposed model of research was developed after conducting a case study in software companies in Tehran province. The most important results of this study are that the main predictors of the model are predictors of "business intelligence for business IT services strategy with data code (A5)" with predictive weight of $0.34 \%$, predictor "business intelligence for continuous improvement of business IT services with data code (A1) with predictive weight $0.30 \%$, predictor "business intelligence for business IT services transfer with data code (A3). Finally, in order to apply business intelligence to improve the organization's information technology management, the top companies were categorized into six groups (Class A-F), with optimal ratios of the likelihood of successful use of BI in the organization.
\end{abstract}

Keywords: Business intelligence; Information technology management; Software companies of Tehran province: Data mining technique; Clementine environment

\section{RESUMEN}

El propósito de este estudio fue investigar el efecto de la aplicación de inteligencia empresarial en la mejora de la gestión de la tecnología de la información de la organización basada en datos de empresas de software en la provincia de Teherán utilizando técnicas de minería de datos en el entorno Clementine titulado BI-IT.DM. Los datos se basan en una muestra de 12.000 datos e informes de empresas de software en la provincia de 
Teherán durante los años 2013 a 2018, disponibles en la Organización del Gremio de Computadoras de Irán. El modelo de investigación inicial y propuesto se desarrolló después de realizar un estudio de caso en empresas de software en la provincia de Teherán. Los resultados más importantes de este estudio son que los principales predictores del modelo son predictores de "inteligencia empresarial para la estrategia de servicios de $\mathrm{TI}$ empresarial con código de datos (A5)" con un peso predictivo del $0,34 \%$, predictor "inteligencia empresarial para la mejora continua de servicios de TI empresarial con código de datos (A1) con peso predictivo 0,30\%, predictor "inteligencia empresarial para la transferencia de servicios de TI empresarial con código de datos (A3). Finalmente, con el fin de aplicar inteligencia empresarial para mejorar la gestión de tecnologías de la información de la organización, las principales empresas se categorizaron en seis grupos (Clase A-F), con índices óptimos de probabilidad de uso exitoso de BI en la organización. inteligencia empresarial, gestión de tecnologías de la información, empresas de software de la provincia de Teherán, técnica de minería de datos, entorno Clementine.

\section{INTRODUCTION}

Today, many organizations use business intelligence systems to improve their decision-making processes. Of the organizations that used business intelligence systems, all of them were not successful (FARAJl, 2018).

The more organizations have processes, the more they will need realistic and practical programs to improve the organization's information technology management as a strategic resource for future continuous improvements. On the other hand, today, information technology strategic planning to improve the organization's information technology management is one of the essential factors of the integration of information technology and information technology to improve the organization's information technology management and to achieve competitive advantage. Despite the importance of this issue, we still report numerous failures of organizations in this field (KEIKHANI, 2017).

Business intelligence is the most important topic selected by Gartner in his 2017 strategic process reports. Business intelligence covers the tasks of collecting and analyzing large volumes of internal systems and external resources, and this may, because business intelligence utilizes advanced analytics and rapid forecasting tools that help an organization make timely and immediate decisions to achieve its goals (JALALI AGHDAM \& KHADEMI, 2018). 
The main purpose of business intelligence is to help organizations improve their performance and enhance their competitive advantage in the marketplace. Knowledge management and business intelligence are very important in any organization.

But this is more important in knowledge-based organizations whose existential philosophy is the production and dissemination of knowledge. Today, due to the intensification of the competitive environment, countries and firms are not only relying on limited internal organizational resources or random information gained from the surrounding space, but in fact having accurate and effective information, in deciding and adopting their competitive strategy. One of the power tools at national and corporate level is (BALACHANDRAN \& PRASAD, 2017; TRIGO, ET AL. 2016).

Therefore, organizations try to obtain the best information sources in their organization environment and use them effectively in their strategic planning (JALALI AGHDAM \& KHADEM, 2018).

In fact, the issues of this research can be the ambiguity of the decision makers and managers of the organization's information technology to explore the use of business intelligence for business IT services strategy, business intelligence for design of business IT services, business intelligence for business IT services transfer, business intelligence for operation of business IT services, business intelligence for continuous improvement of business IT services and evaluating the relationship between "organizational operations analysis", "product planning", "financial account management", "supply chain management", "sales force automation" and improved organization information technology management, as well as the need to use data mining methodology in the clementine environment for using business intelligence for improvement of business IT services to increase trust and confidence in decision-making, stated. In the present study, applying business intelligence to improve the organization's information technology management using data mining technique in clementine environment entitled BI-IT.DM is presented for the first time in a related field of research. 


\section{THEORETICAL FOUNDATION AND RESEARCH BACKGROUND}

Information technology is one of the most important competitive advantages in the world of business whose importance is undeniable and overlooked (NIASTI \& KARIMI, 2018). Today, information forms the cornerstone of any operation, so if it to be economic, commercial or trade (SALIMI ET AL., 2018).

How to access, collect and process information has become the basis of a new science called information technology. Businesses as one of the branches of applied sciences have not suffered from these changes and due to the problems and issues that exist in the business sector; the necessity of using this technology has become increasingly apparent (SALIMI ET AL., 2018).

Since information and communication technology is one of the indicators of sustainable development, it can support many ICT tools to meet the needs of the community and move it towards sustainable development (QOSARI AND YEKATAEI, 2016; ESFANDIARPOUR AND MAHDAVI NIA, 2017).

The purpose of using business intelligence in these institutions is to collect, process, and analyze large volumes of data and convert them into effective business value in decision making through the creation of analytical intelligent reporting platforms (ZAREI \& ZAREI, 2018). The necessity of applying successful business intelligence in organizations in the knowledge age and in the information society can be considered from different perspectives. From the viewpoint of senior managers, using business intelligence tools to analyze the current status of the organization, setting short-term, long-term goals and controlling the performance indicators are essential. From the perspective of executive management for decision making in uncertain and ambiguous environments and predicting and estimating decision-making outcomes, from the perspective of financial management to monitor and control the financial reports and performance indicators, from the perspective of chain management to control and improve relationships with suppliers and partners of the organization, from customer relationship management viewpoint for identification, 
classification, policy-making and improve communication with customers and other organizations (FARAHI ET AL., 2015).

Modern business intelligence technologies are highly integrated and easily deployed and used as business intelligence packages. To apply a successful business intelligence solution in different organizations and maximize the end-user benefits, business intelligence technologies must be organized. These technologies must be deployed in an infrastructure that can implement the business intelligence process. This infrastructure is the same as business intelligence platform (SUN, ET AL. 2018; LIANG \& LIU, 2018; KIKAI ET AL., 2017, OLSON, ET AL., 2018).

\section{2-1 Research background}

Orta \& Ruiz (2019) aimed at analyzing commercial intelligence and analyzing value creation: the role of absorption capacity, and we expand our theoretical understanding of how $\mathrm{Bl}$ insights can be transformed into valuable knowledge. We find a lot of attention to the role of $B I \& A$ in organizational cognition. The empirical findings show that the absorption capacity is affected by the knowledge production process of BI. We have identified technology, human and communication assets for the $\mathrm{Bl}$ infrastructure. In addition, this process is supported by technological, human and relational assets.

Orta \& Ruiz (2018) examined "process management within the information technology organization (ITIL) information resources using strategic information resources management": strategic information resources management expected to be one of the rapidly growing technologies in the coming years, organizational applications will be the largest market for IT service costs, with a gradual shift from assumption-based services to expected business applications in general, such as the benefits of business IT management and improved information technology management, organization resource planning arrive cloud computing arena. But before moving to the cloud, organizations must consider datadriven issues such as confidentiality, security, compliance, standards interoperability, and quality of service. 
Gharibi et al. (2018) concluded that organizations should move from customer focus to product focus in competitive markets, focusing on product, and managing their behavior to provide maximum efficiency to their organization. In this study, we investigate business intelligence, constituent components of business intelligence, and by reviewing previous studies in this field, we present a conceptual model for identifying effective factors in applying business intelligence.

Tashakori and Tavalaee (2018) found that data is now considered a valuable asset of organizations and governments, even more valuable than oil. The findings show that applying business intelligence has a direct impact on risk management, asset and debt management, selling complementary products to existing customers, reducing corporate loan interest rates, customer categorization, and customer life cycle management, which creates productivity in each of these cases. It creates a competitive advantage for organizations.

Naimi Rad et al. (2018), business intelligence systems were designed with a focus on the back-end, but today the architecture of business intelligence has shifted to enterprise analytics applications and distributed multilayer applications. In this study, the role of business intelligence in banking and the necessity of using business intelligence along with its functions in organizations have been explained and the proposed architecture of data in the data repository has been presented using the ETL triple process. Business intelligence means giving the right information to the right people at the right time to make the right decision.

Faraji et al. (2018) seeks to identify critical success factors that affect the success of implementing business intelligence systems in organizations. The results of this study are very useful for scientists and managers to identify issues related to business intelligence projects in Iran. As such, this research aims to move toward a better understanding. With localization, we examined the critical factors for the success of commercial intelligence in Iran.

Pourmirzae Kouhbanaee and Naserassadi (2016), it was stated that the process of globalization, along with the development of information technology and information 
systems, as well as the virtualization of the organization's environment had a profound effect on the way organizations operate. And, on the other hand, organizations that have failed to make the necessary convergence between information technology strategies of the organization have faced significant financial costs and lost opportunities. In this research, first, a definition of information technology strategy and organization strategy is presented, and then we present the necessary steps for achieving strategic alignment and examining Lufthman's strategic maturity maturity model.

\section{METHODOLOGY}

In this study, the facts and issues surrounding the use of business intelligence in improving the organization's information technology management are surrounded by a variety of social, political, cultural, economic, ethical, and other factors that influence decision-making. By using $\mathrm{Bl}$, they become transparent over time and when interacting with organization members.

In fact, this research is applied in nature because its results and findings are used to solve issues related to $\mathrm{Bl}$ application, which is one of the specific problems of the organization. On the other hand, philosophical assumptions employ alternatives with technological-social themes for the design approach to ontology from a multiple ontology perspective. From the epistemological point of view of this study, the researcher comprehensively evaluates the phenomenon under study in an interactive way. Here the subjectivity and values of the field under study will affect the phenomenon. The purpose of this paper is model-analytic in terms of purpose, because it delivers precise descriptions of the concepts and rules related to $\mathrm{BI}$ application and on the other hand the relationships between these concepts and rules are evaluated and determined by data mining techniques. It is used for library studies, internet access, dissertation studies, books, articles in domestic and foreign journals, study of statistics and documents cited and published by the university. Due to the use of articles and documents related to $\mathrm{BI}$ application from various sources, the method of data gathering in this paper is "case study documentation" and data mining techniques have been used for BI application. 
Since the interactive nature of the article "applying business intelligence (BI) to improve information technology management in Tehran province software companies" necessitates a discourse between the researcher and the experts in the field of study, the researcher's misperceptions become knowledge. Today, with the increasing integration of information systems into data systems, a new approach to data analysis has been provided. Organizational data is becoming more and more sophisticated and, in parallel, the information systems of the organization have the task of mechanically performing the transactions related to the organization. The purpose of business intelligence is to provide data analysis methods and tools to improve decision making data.

\subsection{Data collection and population and sample}

This study will use both data and experts. In fact, the data of the present study was compiled based on the data and reports of software companies in Tehran during 2013 to 2018.

The study population of this paper can be divided into two general groups: the first group includes professors in the field of study; and the second group includes IT experts working in software companies in Tehran province.

\subsection{Data analysis methods and tools}

In fact, the steps of the present study to investigate the impact of applying business intelligence on improving information technology management using Markowitz model and data mining tecnique in Clementine environment are:

- Extract information from multiple databases (databases).

- Integrating information and removing redundant data.

- Put modified data in the data warehouse.

- Performs data mining using Clementine software.

- Show results in a comprehensible way such as reports and graphs. 
In the following study, Delphi technique was used for qualitative data analysis, because the Delphi technique can be used for "identification" and "screening" as the most important decision-making indicators.

Therefore, although the Delphi technique is not a multi-criteria decision-making method, in many cases it is used to screen indicators or to reach agreement on the importance of decision-making indicators before applying multi-criteria decision-making techniques.

Applying the expertise and expertise of a set is very helpful in making decisions about issues that are of a qualitative nature. Delphi technique is one of the methods of group knowledge acquisition that is also used in decision making about quality issues. Delphi technique can be used in exploratory qualitative research and identifying the nature and fundamental elements of a phenomenon. The Delphi technique is a structured process for gathering information during consecutive rounds and ultimately group consensus.

\section{RESULTS}

\section{4-1 Data mining to apply business intelligence}

The data of the present study was compiled based on a sample of 12,000 data and reports from software companies in Tehran province during 2013 to 2018, available in the computer industry organization of Iran. In fact, the steps of the present study in applying Clementine software to improve business intelligence management in organization information technology are:

4-1-1 Step One: extracting data from multiple data sources (Database)

Extracting data from several data sources after doing a case study in software companies in Tehran province, and reaching the final model based on the research data items ie, the research objective variable: According to the initial and proposed research model, the following is done: using reports and documentation of software companies in Tehran province during 2013 to 2018, a dataset based on a sample of 12,000 of these data 
as research datasets to apply business intelligence to improve organization information technology management based on software companies in Tehran province. Data mining techniques were developed. An overview of the pattern of applying business intelligence to improve the organization's information technology management is as follows:

Fig 1- Overview of the pattern of applying business intelligence in improving the organization's information technology management

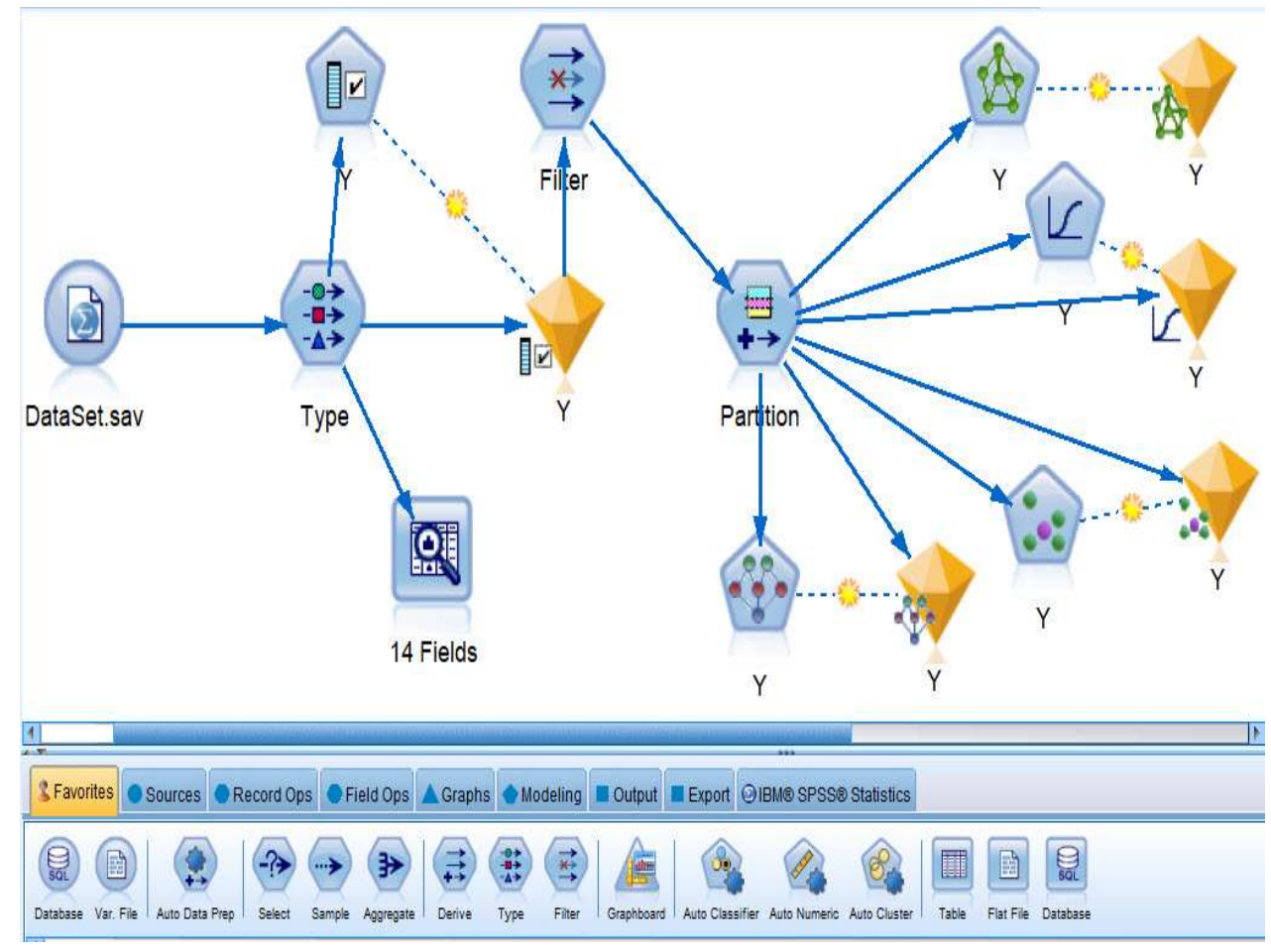

Source: Authors (2020)

The figure below shows the algorithms and macro view of the data mining techniques used in Clementine software.

\section{4-1-2- Second step: Integrating data and removing redundant data}

In order to convert data types to more complex transformations such as defining new attributes by performing mathematical and logical operations on existing attributes, the following has integrated information and eliminates redundant data in applying business intelligence to improve information technology management in an organization: 
Fig 2- Integration of data and removal of redundant data

\begin{tabular}{|c|c|c|c|c|c|}
\hline$\underline{v}$ & $\sqrt{v}$ & Rank & 1 A & & \\
\hline & Rank : & Field & Measurement & Importance & Value \\
\hline$\checkmark$ & & $2\langle A\rangle C 1$ & $\&$ Continuous & Important & 1.0 \\
\hline$\nabla$ & & $3\langle 4 \Rightarrow 3$ & $\&$ Continuous & Important & 0.949 \\
\hline$\nabla$ & & $4\langle A$ A1 & $\&$ Continuous & Important & 0.923 \\
\hline$\checkmark$ & & $5\langle\hat{A}\rangle \mathrm{A} 5$ & $\&$ Continuous & Important & 0.922 \\
\hline$\checkmark$ & & $6\langle\pi\rangle A 3$ & $\&$ Continuous & Important & 0.917 \\
\hline$\checkmark$ & & 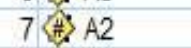 & $\&$ Continuous & + Marginal & 0.659 \\
\hline$\checkmark$ & & $8\langle\hat{A} \geqslant \mathrm{~A} 4$ & $\&$ Continuous & + Marginal & 0.614 \\
\hline D & & $9\langle$ ity $B 2$ & $\&$ Continuous & - Unimportant & 0.486 \\
\hline 国 & & $10\langle\ddot{C}>3$ & $\&$ Continuous & - Unimportant & 0.459 \\
\hline 国 & & $11\langle\ddot{C}\rangle 2$ & $\&$ Continuous & - Unimportant & 0.355 \\
\hline 国 & & $12\langle\bar{\pi} \geqslant \mathrm{B} 4$ & $\&$ Continuous & - Unimportant & 0.162 \\
\hline D & & $13\langle$ A $B 1$ & $\&$ Continuous & - Unimportant & 0.143 \\
\hline Sele & ed fields: 7 & Total fields & lable: 13 & & \\
\hline & & & 由 $>0.8 \square<=0.8 \quad \bullet$ & & \\
\hline
\end{tabular}

Source: Authors (2020)

As it can be analyzed, after data integration and redundant data deletion, it was found that data items reduce organization costs with data code (C1) having a value of $1(100 \%)$; sales force automation with data code (B3) with value of $0.949 \%$, business intelligence for continuous improvement of business IT services with data code (A1) with value $0.923 \%$, business intelligence for business IT services strategy with data code (A5) with value 0.922\% business intelligence for business IT services transfer with code data (A3) with value $0.917 \%$ and business intelligence for operation of business IT services with data code (A2) with value $0.659 \%$ and business intelligence for design of business IT services with data code (A4) with value of $0.614 \%$, determined as data points of applying business intelligence to improve the organization's information technology management based on the software companies' datasets of Tehran Province.

And items such as supply chain management with data code (B2), analysis of business operates with data code (B4), financial account management with data code (B5), improving flexibility and scalability of the organization with data code (C2) and fast services to customers with data code (C3); with value less than 0.5 , due to the principle of waste data removal, they were excluded from the research model. 
4-1-3 Step Three: put modified information in data warehouse

Using data audit in Clementine software, in order to apply business intelligence to improve the organization's information technology management, it was found that the number of valid data based on 12 data is in good condition. Correct and consistent information is one of the requirements we need in data mining. Inaccurate information leads to incorrect conclusions resulting in incorrect decisions in organizations and will lead to dangerous results that are not low in the sample:

Table 1- Modified data in data warehouse

\begin{tabular}{|c|c|c|c|c|}
\hline Data items & $\begin{array}{l}\text { Minimum } \\
\text { data }\end{array}$ & $\begin{array}{l}\text { Maximum } \\
\text { data }\end{array}$ & $\begin{array}{c}\text { Mean } \\
\text { Markowitz } \\
\text { variance }\end{array}$ & $\begin{array}{l}\text { Valid } \\
\text { data }\end{array}$ \\
\hline $\begin{array}{l}\text { Business intelligence for } \\
\text { continuous improvement } \\
\text { of business IT services (A1) }\end{array}$ & 27 & 80 & 59.917 & 12 \\
\hline $\begin{array}{l}\text { Business intelligence for } \\
\text { operation of business IT } \\
\text { services (A2) }\end{array}$ & 59 & 121 & 78.083 & 12 \\
\hline $\begin{array}{l}\text { Business intelligence for } \\
\text { business IT services } \\
\text { transfer (A3) }\end{array}$ & 31 & 122 & 80.167 & 12 \\
\hline $\begin{array}{l}\text { Business intelligence for } \\
\text { design of business IT } \\
\text { services (A4) }\end{array}$ & 31 & 168 & 76.25 & 12 \\
\hline $\begin{array}{l}\text { Business intelligence for } \\
\text { business IT services } \\
\text { strategy (A5) }\end{array}$ & 36 & 80 & 57.333 & 12 \\
\hline $\begin{array}{l}\text { Sales force automation } \\
\text { (B3) }\end{array}$ & 34 & 105 & 70.75 & 12 \\
\hline $\begin{array}{l}\text { Financial account } \\
\text { management (B5) }\end{array}$ & 41 & 77 & 54.917 & 12 \\
\hline $\begin{array}{l}\text { Improving flexibility and } \\
\text { scalability of the } \\
\text { organization (C1) }\end{array}$ & 27 & 73 & 48.417 & 12 \\
\hline
\end{tabular}


Analyzing the data audit to apply business intelligence to improve the organization's information technology management revealed that all research data (12 data items) were $100 \%$ valid (12 data out of 12 data) and business intelligence for business IT services transfer (A3) with mean Markowitz variance of $80.167 \%$, business intelligence for operation of business IT services (A2) with mean Markowitz variance of $78.083 \%$ and Business intelligence for design of business IT services (A4) with mean Markowitz variance of 76.25 as one of the most important indicators of applying business intelligence in improving information technology management in software companies of Tehran were calculated.

In the data partition section, the inputs were divided into two classes of training data ( $80 \%$ data) and test ( $20 \%$ data), so that the data of the training section first determined the optimal model through the simulation process, then are tested in Part II. And then the rank of each category is determined. Information on selected data items (inputs) was determined as codes for applying business intelligence to improve the organization's information technology management. In fact, the predictive power of applying business intelligence in improving information technology management of an organization using data mining techniques is as follows: regression model and Bayesian research networks:

Fig 3- Predictive power of the research model

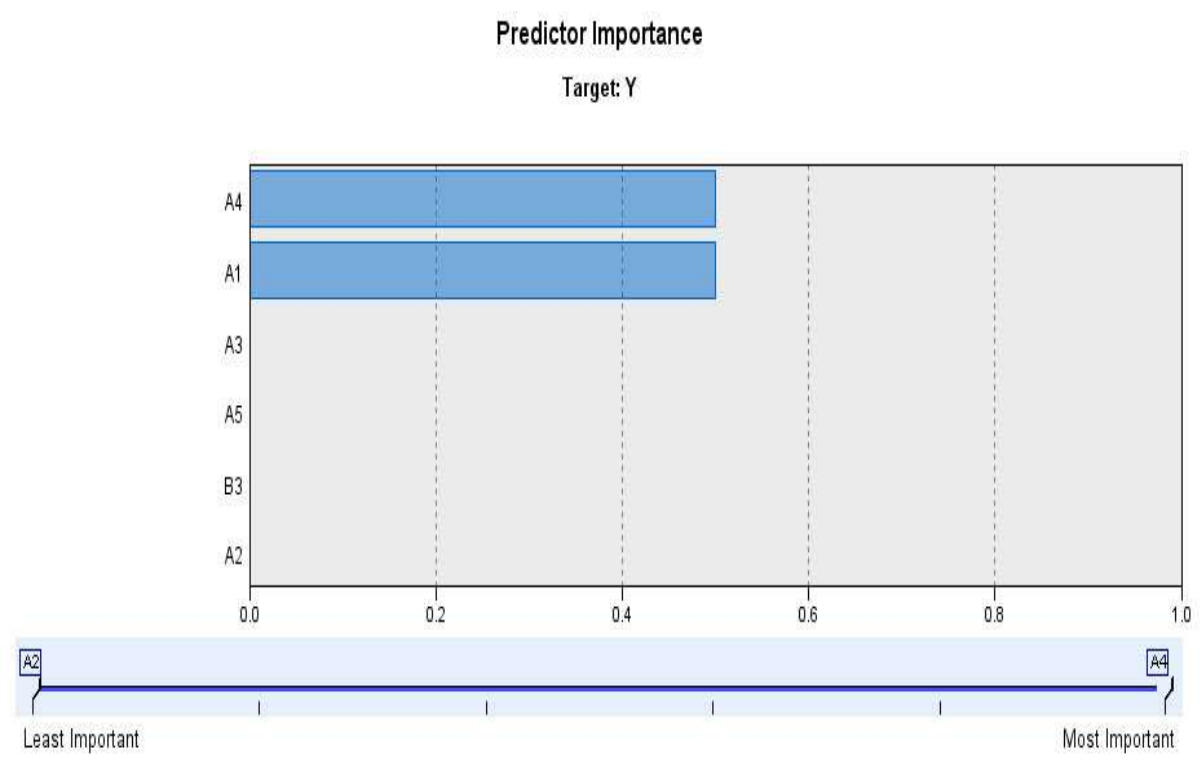

Source: Authors (2020) 
Fig 4- Predictive power of the research model

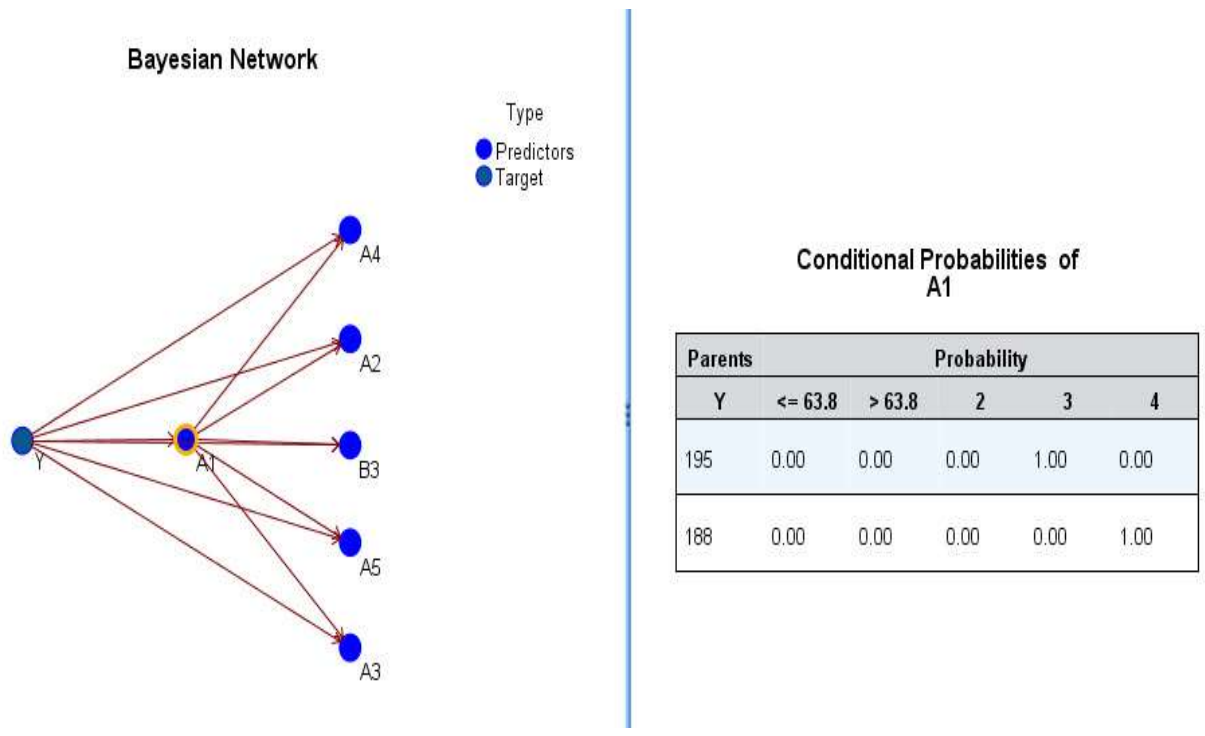

Source: Authors (2020)

Analyzing the predictive power of business intelligence for improvement of business IT services based on software data of Tehran province software companies, it was found that the research model has a high predictive power, because in the regression model calculations, business intelligence for continuous improvement of business IT services (A1) with power of $0.50 \%$ and business intelligence for design of business IT services (A4) with power of $0.50 \%$ were calculated as the most important predictors of regression model and Bayesian research networks, respectively.

\section{4-1-1 Step Four: perform advanced data mining operations}

To complement data mining operations by Clementine software, K-Nearest Neighbors (KNN) data mining technique is used to identify patterns in applying business intelligence to improve organization information technology management based on data from software companies in Tehran province using data mining techniques. The following diagram shows the output of the K-Nearest Neighbors (KNN) data mining technique for data: 
Fig 5- Output of K-Nearest Neighbor (KNN) technique of research model

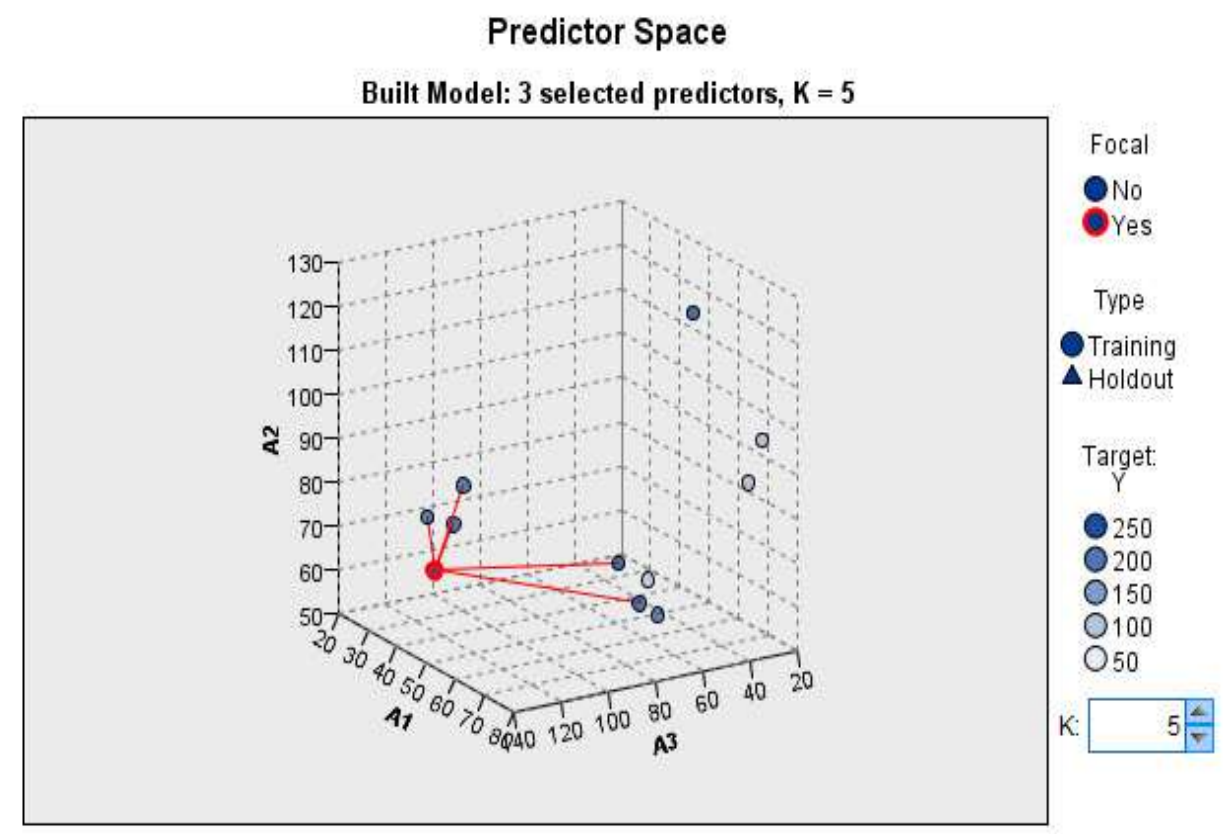

Source: Authors (2020)

Method K- Nearest Neighbor in the present study, a group consisting of $\mathrm{K}$ records was selected from the set of training records that are closest to the experimental record and based on their category or label superiority over the test record category, the decision maker and intelligence 3 predictors business intelligence for business IT services transfer (A3) on the X-Axis, business intelligence for continuous improvement of business IT services (A1), at $Y$ Axis and Business intelligence for operation of business IT services (A2) at Z Axis, as the $K$ nearest neighbors (KNN) of the model is calculated.

The Artificial Neural Network (ANN) output in Clementine software for a more accurate analysis and application of business intelligence to improve the organization's information technology management is shown below:

Continue... 
Fig 6- Output of Artificial Neural Network (ANN) of research model

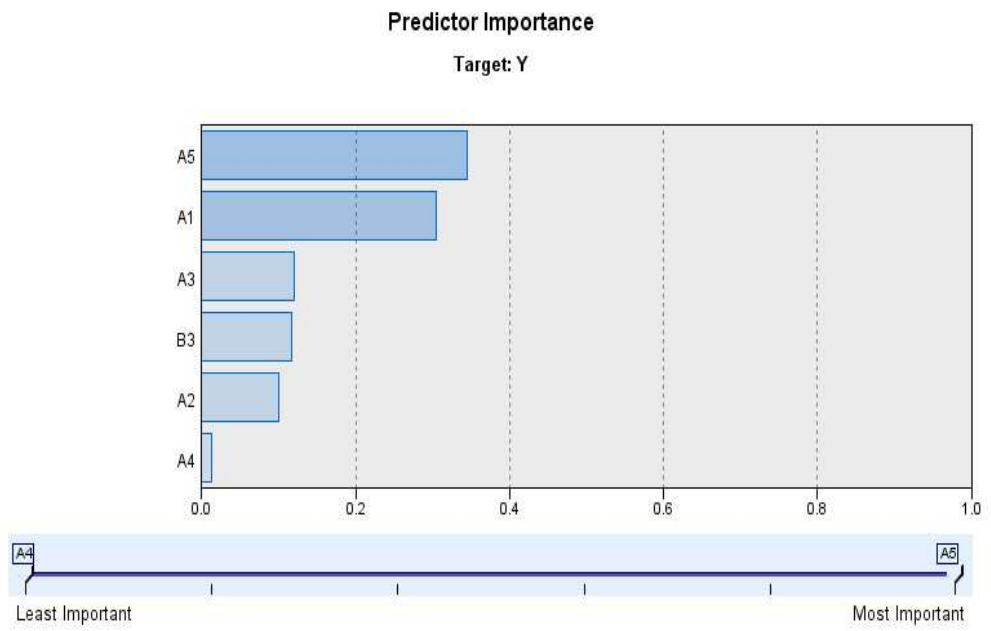

Source: Authors (2020)

Fig 7 - Output of Artificial Neural Network (ANN) of research model

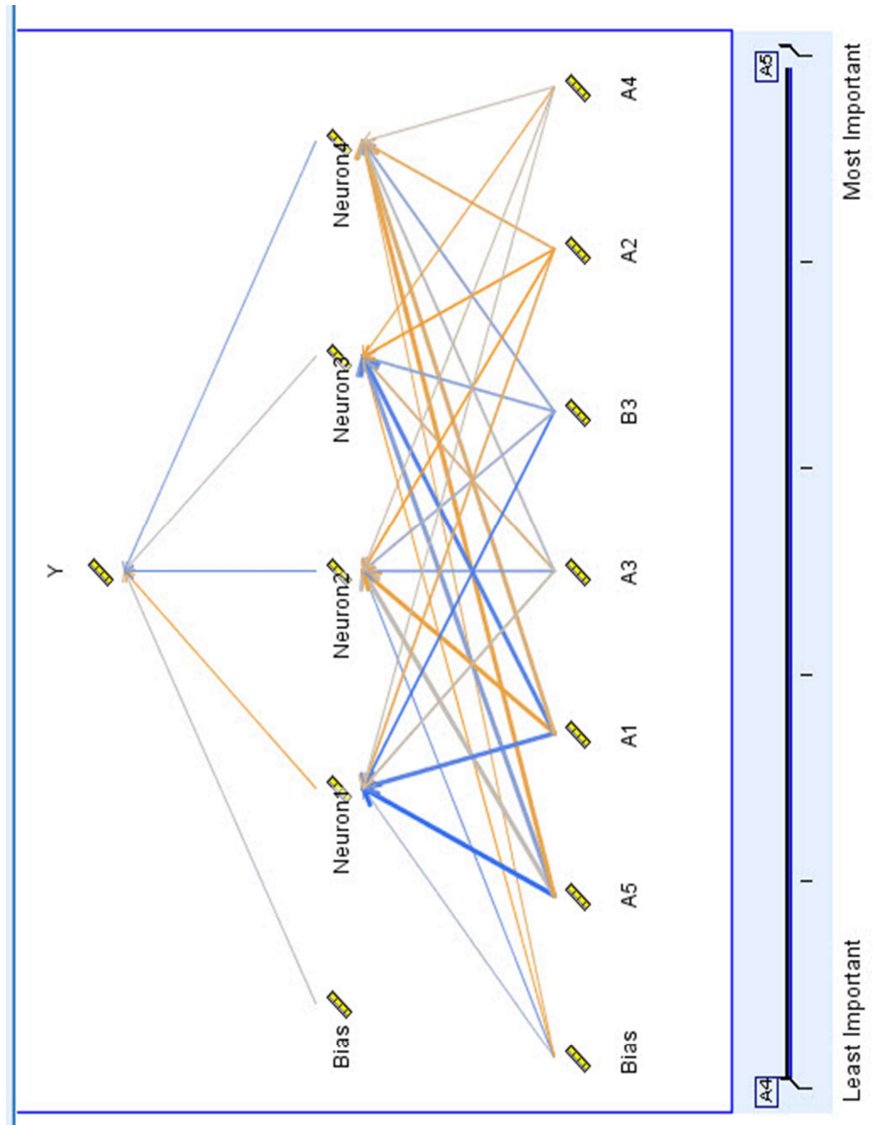

Source: Authors (2020) 
Analyzing the artificial neural network output for a more accurate analysis and applying business intelligence to improve the organization's information technology management, it was found that blue colors have a positive estimation in the research model, which are the main predictors of the model, respectively, the predictor of business intelligence for business IT services strategy with data code (A5)" with predictive weight of $0.34 \%$, predictor of business intelligence for continuous improvement of business IT services with data code (A1) with predictive weight $0.30 \%$, business intelligence for business IT services transfer with data code (A3) with predictive weight $0.16 \%$, predictor "sales force automation with data code (B3) with predictive weight $0.15 \%$, predictor "business intelligence for operation of business IT services with data code (A2)" with predictive weight $0.10 \%$, predictor "business intelligence for design of business IT services (A4)" with predictive weight 0.02 , have provided a more detailed analysis of the application of business intelligence in improving the organization's information technology management using data mining techniques.

In fact, it was found that top-class companies A (firms with the highest business intelligence for business IT services transfer based on Markowitz mean variance calculations): the first major predictor of research (business intelligence for business IT services strategy) with $34 \%$ probability of using $\mathrm{BI}$ success in the organization, top class $\mathrm{B}$ companies (companies with the highest business intelligence for business IT services operations based on Markowitz mean variance calculations): the second major predictor of research (business intelligence for continuous improvement of business IT services) with $30 \%$ chance of success in deploying $\mathrm{BI}$ in the organization, top class $\mathrm{C}$ companies (companies with best business intelligence for design of business IT services based on mean Markowitz calculations: third main predictor of research (business intelligence for business IT services transfer) with 16\% chance of success in deploying $\mathrm{BI}$ in the organization, top class D companies (companies with best performance in sales force automation based on mean Markowitz's variance calculations): fourth major predictor of research (sales force automation) with 15\% chance of success in deploying $\mathrm{BI}$ in the organization, E top-class companies (companies with the most financial account management based on mean Markowitz's variance calculations), fifth 
main predictor of research (business intelligence for operations of business IT services) with $10 \%$ chance of success in deploying $\mathrm{BI}$ in the organization, and $\mathrm{F}$ top-class companies (companies with top business intelligence for business IT services strategy based on mean Markowitz's variance calculations): sixth main predictors of research (business intelligence for design of business IT services) with $2 \%$ chance of success in deploying BI deployment in the organization.

\section{DISCUSSION}

The main findings of the study are presented to reach the purpose of the study and with respect to the research background. In fact, the data of the present study was compiled based on a sample of 12,000 data and reports from software companies in Tehran province during 2013 to 2018, available in the Organization of Computer Guild of Iran. In fact, the steps of the present study to apply business intelligence to improve the organization's information technology management based on the software data of Tehran province software companies in Clementine software are:

Step One: Extracting data from multiple sources (database): extracting data from multiple data sources based on the research data items, according to the initial and proposed research model, the following is the figure and table. Using reports and documentation of software companies in Tehran province from 2013 to 2018, a dataset based on a sample of 12,000 of these data as research datasets to apply business intelligence to improve organization information technology management using data mining techniques.

Step Two: Integrating data and removing redundant data: to convert a data type to another to make more complex transformations such as defining new attributes by performing mathematical and logical operations on existing attributes, here, integrating information and removing redundant data in the use of intelligence. The organization's information technology management was addressed. As it can be analyzed, after data integration and redundant data deletion, it was found that data item and product planning with data code (B1) with value of 1 (100\%); sales force automation with data code (B3) with 
value of $0.949 \%$, business intelligence for continuous improvement of business IT services with data code (A1) with value $0.923 \%$, business intelligence for business IT services strategy with data code (A5) with value $0.922 \%$, business intelligence for business IT services transfer with data code (A3) with value of $0.917 \%$ and business intelligence for operation of business IT services with data code (A2) with margin value $0.659 \%$ and business intelligence for design of business IT services (A4) with margin value $0.614 \%$ were identified as business intelligence data use data to improve organizational information technology management; and managerial data items. And items of supply chain management data with data code (B2), analyzing an organization's operations with data code (B4), financial account management with data code (B5), improving the flexibility and scalability of the organization with data code (C2), and faster service to customer with data code (C3) and reduce organization costs with data code (C1), because of a value of less than 0.5 , due to eliminating redundant data, were excluded from the study.

Step three: put modified information in data warehouse: using data audit in Clementine software, in order to apply business intelligence to improve the organization's IT management, it was found that there were 12 valid data sets in the data state which are in desirable condition. Correct and consistent information is one of the requirements we need in data mining. Inaccurate data leads to incorrect conclusions resulting in incorrect decisions in organizations and will lead to dangerous results that are not low.

Analyzing the data audit to apply business intelligence to improve the organization's information technology management revealed that all research data (12 data items) were $100 \%$ valid (12 data out of 12 data) and business intelligence for business IT services transfer (A3) with mean Markowitz variance of $80.167 \%$, business intelligence for operation of business IT services (A2) with mean Markowitz variance of $78.083 \%$ and Business intelligence for design of business IT services (A4) with mean Markowitz variance of 76.25 as one of the most important indicators of applying business intelligence in improving information technology management in software companies of Tehran were calculated.

Step four: on the other hand, the purpose of the data warehousing process is to provide an integrated environment for information processing. In this process, analytical and 
concise data is organized and stored over time so that it can be used in decision-making processes that are data mining requirements. Analyzing the accuracy of applying business intelligence to improve the organization's information technology management using data mining techniques based on reports and documentation of software companies in Tehran province during 2013 to 2018 , showed that the research model is highly accurate. In the data partition section, the inputs were divided into two classes of training data ( $80 \%$ data) and test ( $20 \%$ data), so that the data of the training section first determined the optimal model through the simulation process, then are tested in Part II. And then the rank of each category is determined. Information on selected data items (inputs) was determined as codes for applying business intelligence to improve the organization's information technology management.

Analyzing the predictive power of applying business intelligence to improve organizational information technology management, it was found that the research model has a high predictive power because in the regression model calculations, data items of business intelligence data points for continuous improvement of business IT services with data code (A1) with a power of $0.50 \%$ and business intelligence for design of business IT services with data code (A4) with power of $0.50 \%$ were calculated as the most important predictors of the regression model and Bayesian research networks, respectively.

On the other hand, in order to more precisely analyze and apply business intelligence in improving information technology management of organization using data mining techniques, based on reports and documentation of software companies of Tehran province from 2013 to 2018, from ANN for data mining technique in Clementine software because in this part of the research new computational methods are needed for machine learning, knowledge demonstration, and finally applied knowledge to predict the output responses of complex systems because neurons in a collaborative process need to work together. In the data partition section, the inputs were divided into two classes of training data $(80 \%$ data) and test ( $20 \%$ data), so that the data of the training section first determined the optimal model through the simulation process, then are tested in Part II. 


\section{CONCLUSION}

The most important finding in the research "applying business intelligence to improve organizational information technology management using data mining technique in Clementine environment" is that by analyzing artificial neural network output for more accurate analysis and applying business intelligence to improve IT management. Blue colors have positive estimates in the research model, respectively, which are predictors of business intelligence for business IT services strategy with data code (A5)" with predictive weight of $0.34 \%$, predictor "business intelligence for continuous improvement of business IT services with data code (A1) with predictive weight $0.30 \%$, predictor "business intelligence for business IT services transfer with data code (A3) with predictive weight $0.16 \%$, predictor "sales force automation with data code (B3) with predictive weight $0.15 \%$, predictor "business intelligence for operation of business IT services with data code (A2)" with predictive weight $0.10 \%$, predictor "business intelligence for design of business IT services (A4)" with predictive weight 0.02 , have analyzed more precisely the application of business intelligence in improving the organization's information technology management using data mining techniques. Finally, it was found that the aforementioned predictors could predict with $86 \%$ accuracy the use of business intelligence in improving the organization's information technology management using data mining techniques.

The following table compares the most important results and findings of the present study with those of the most relevant researches in theoretical literature:

Continue... 
Table 2- Comparison of the findings of the most relevant researches in theoretical literature with the findings of the present study

\begin{tabular}{|c|c|c|c|c|c|c|c|c|c|c|c|c|c|c|}
\hline \multirow[t]{2}{*}{ z } & \multirow[t]{2}{*}{ Research title } & \multirow[t]{2}{*}{ 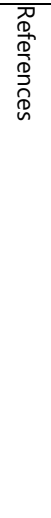 } & \multicolumn{12}{|c|}{$\begin{array}{l}\text { Comparison of research findings } \\
\text { (Research Innovations) }\end{array}$} \\
\hline & & & 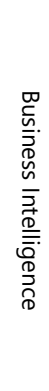 & 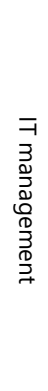 & 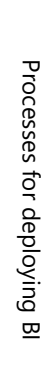 & 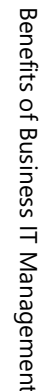 & 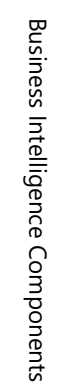 & 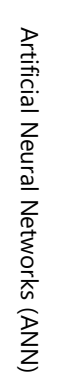 & 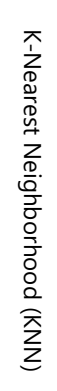 & 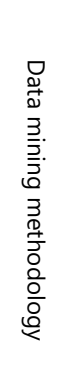 & 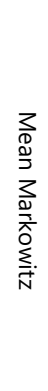 & 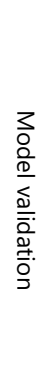 & 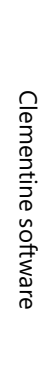 & 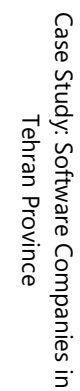 \\
\hline
\end{tabular}

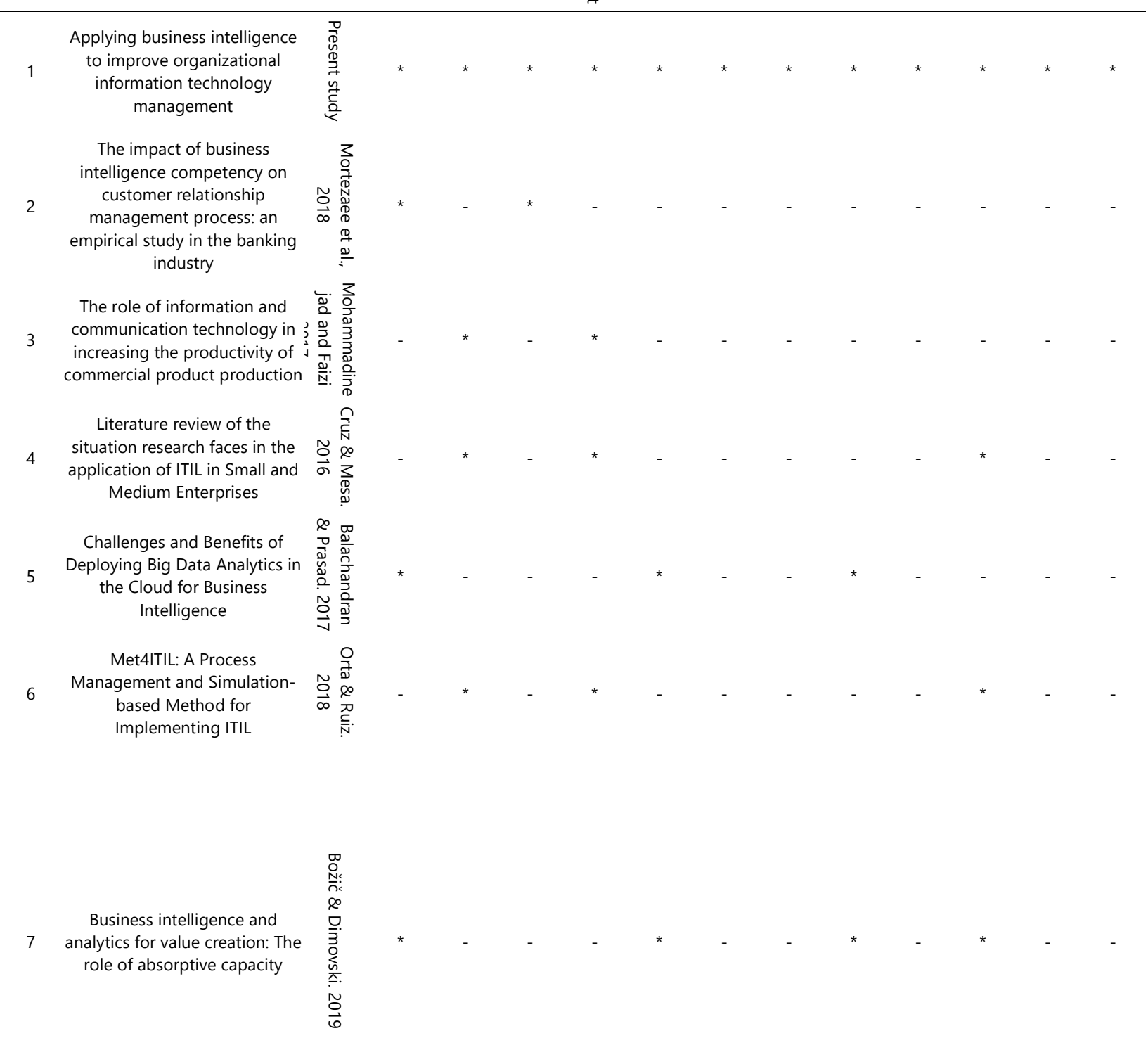


Finally, the scientific implications of this study and suggestions for other researchers to continue their work will be addressed. In fact, the most important and key suggestion of the present study for applying business intelligence in improving the organization's information technology management is to improve business intelligence for continuous improvement of business IT services; business intelligence for operation of business IT services; business intelligence for business IT services transfer; business intelligence for design of business IT services; business intelligence for business IT services strategy; reduce organization costs; improve organizational flexibility and scalability; faster service to customer; product planning; supply chain management; operational planning and sales automation; product planning should pay special attention to the strategic decisions of software companies in Tehran province, because senior managers of the IT industry need to help improve the services of software companies in Tehran.

\section{REFERENCES}

BALACHANDRAN, B. M., \& SHIVIKA, P. Challenges and Benefits of Deploying Big Data Analytics in the Cloud for Business Intelligence. Procedia Computer Science, Volume 112, 2017, Pp. 1112-1122, 2017.

BOŽIČ, K., \& VLADO, D. Business intelligence and analytics for value creation: The role of absorptive capacity. International Journal of Information Management, Volume 46, June 2019, Pp, 93-103, 2019.

ESFANDIARPOUR, I., AND SEYED MOHAMMAD, M. A Study of Information Technology, Strategy Concentration, and Organizational Structure and Their Impact on Organization Performance Case Study: Cosmetics and Hygiene Factories, Second International Conference on Management and Accounting, Tehran, Iran, 2017.

FARAHI, A., SHOJAEI K., SEYYED, M., BUKHARAI NIA, M. Necessities, Prerequisites, Challenges of Applying Successful Business Intelligence in Organizations, International Conference on Management, Economics and Industrial Engineering, pp. 13-19, 2015.

FARAJI, Z., MAHTAB, J., AND MOHAMMAD, R. Vital factors of success in implementing business intelligence systems in small and medium enterprises (Case Study: Iran), International Conference on Innovation and Research in Engineering Sciences (ICIRES 2018), Georgia Tbilisi, International Academy of Sciences of Georgia - Payam Noor University, 2018.

GARSHASBI, M., AND FARSHID, S. Application of Commercial Intelligence System in Banking Industry, Case Study of Saman Organization, Second National Conference on Knowledge and 
Technology of Iranian Engineering Sciences, Tehran, Sam Iranian Institute of Knowledge and Technology Development Conference, 2019.

GHARIBI CREEK, S. J., AMENE, A., ALIREZA, E., AND JAMAL, M. K. A Model for Identifying Factors Affecting the Application of Business Intelligence, Fifth International Conference on New Science and Technology-Based Research in Service, Islamic Studies and Researches, Tehran, 2018.

GHOSARI, N., AND MOHAMMAD HOSSEIN, Y. Presentation of an Improvement Model Using Organizational Information Technology Framework Using Prioritization Algorithm in Organizations (Case Study), Fourth International Conference on Economics, Management, Accounting with Creation Value Management, Shiraz, NARON Expert Managers Training Institute, 2016.

JALALI AGHDAM, D., AND MORTEZA KHADEMI, S. The Importance of Business Intelligence, Organizational Resources and Knowledge Management in Organization Promotion and Competitive Advantage, 2nd National Conference on Knowledge and Technology of Iranian Engineering Sciences, Tehran, Institute of Knowledge-Based Conferences and Development Sam Iranian technology, 2018.

KEIKHAEI, A., MAHDIEH, N., MAHTAB, A., AND MOHAMMAD, GH. The Impact of EPR Organizational Resource Planning on Zahedan International Airport Services From the Perspective of Passengers, Second International Congress on Community Empowerment in Management, Mehdi, Farhangi, Tehran, Cultural and social skills of the community, 2017.

LIU, B. Outlier Detection Data Mining of Tax Based on Cluster.Physics Procedia, Volume 33, 2012, Pp, 1689-1694, 2012.

MOHAMMADNEJAD, M., AND HASSAN, F. The Role of Information and Communication Technology in Increasing Productivity of Commercial Products Production, 4th National Conference on Information Technology, Computer and Telecommunication, Mashhad, Torbat Heydariyeh University, 2017.

MORTEZAEE, A., MOHAMMAD SADEGH, S., SALMAN NAZARI, SH., JAFAR, R. Investigating the Impact of Business Intelligence Competency on Customer Relationship Management Process: An Empirical Study in the Banking Industry. Information Technology Management Quarterly. Research 127, Volume 10, Number 1, Spring 1977, pp. 209-234, 2018.

NAIMI RAD, M., HAMED, F., AND VIANA, V. Explaining the Need for Using Business Intelligence in Organization Systems, 5th National Conference on Applied Research in Management and Accounting, Tehran, Iranian Management Association, 2018.

NIASTI, S., AND POURIA, K. Exposure to Small and Medium-sized Enterprises (SMEs) with Technology Transfer: Analysis and Investigation of Factors Affecting Technology in SMEs, 5th National Conference on Applied Research in Management and Accounting, Tehran, Iranian Management Association, 2018. 
OLSON DAVID, L., BJORN JOHANSSON, R., ATEM DE, C. Open source ERP business model framework, Robotics and ComputerIntegrated Manufacturing, Volume 50, April 2018, Pp, 30-36, 2018.

ORTA, E., \& MERCEDES, R. Met4ITIL: A Process Management and Simulation-based Method for Implementing ITIL. Computer Standards \& Interfaces, In press, accepted manuscript, Available online 11, April, 2018.

POURMIRZAEI KOUHBANI, S., NASERASSADI, A. Investigating Methods of Information Technology Strategy and Organizational Strategy, 6th Conference of New Researches in Science and Technology, Kerman, Sky Science Organization, 2016.

SALIMI, M., POUDRBANI, R., AND BAGHER, A. NO. Investigating the Factors Affecting the Adoption and Application of Information Technology in Business, 11th National Congress of Biosystems and Mechanization of Iran, Hamadan University of Technology, Mahaizin, Maoiseiz University, 2018.

SUN, X. 2018. Detecting users' anomalous emotion using social media for business intelligence. Journal of Computational Science, Volume 25, March 2018, Pp, 193-200, 2018.

TAGHAVI FARD, M. T., AND NADALI, A. Classification of Organizational Credit Facility Applicants Using Data Mining and Fuzzy Logic. Industrial Management Studies: Summer 2012, Volume 9, Number 25; pp, 85-107, 2012.

TASHAKORI, M. H., AND ROUHOLLAH, T. Investigating the Use of Business Intelligence in the Banking Industry as a Competitive Advantage, International Conference on Management, Accounting, Banking and Economics in Iran Horizon 1404, Mashhad, Kamarosh Knowledge Cooperative Institute, 2018.

TRIGO, A. Accounting Information Systems: Evolving towards a Business Process Oriented Accounting. Procedia Computer Science, Volume 100, 2016, Pp, 987-994, 2016.

ZAREI, B., AND JALEH, Z. The Effect of Business Intelligence on Financial Performance of Iranian Companies (with Emphasis on Corporate Health Indicators). Journal of Applied Economic Studies in Iran. Research 5, Volume 7, Number 25, Spring 2018, pp. 111-130, 2018.

\section{AUTHORSHIP CONTRIBUTION}

\section{1- Mohamad Ali Noruozzadeh}

Department of Business Administration

https://orcid.org/0000-0003-3142-3092 | E-mail; noruozzadeh@aftermail.ir

Contribuition: Project administration, Supervision, Data curation, Writing-review \& editing, Investigation, Resources, Conceptualization, Visualization, Methodology, Software, Funding acquisition, Validation, Formal Writing - original draft, Analysis 


\section{HOW TO QUOTE THIS ARTICLE}

Noruozzadeh, M. A. The Effect of Applying Business Intelligence on Improvement of Information Technology Management (Case Study: Software Companies in Tehran Province). Revista de gestão, educação e tecnologia ambiental, v.25, e6, 2021. Available from: https://doi.org/10.5902/2236117063799. Accessed: Month Abbreviated. Day, year. 